\title{
PENGEMBANGAN E-RUBRIC DENGAN PENDEKATAN COMPETENCY-BASED ASSESSMENT PADA BIDANG KEAHLIAN AKOMODASI PERHOTELAN DI SEKOLAH MENENGAH KEJURUAN
}

\author{
Neni Rohaeni' ${ }^{1}$ Yoyoh Jubaedah², Nenden Rani Rinekasari'3 ${ }^{3}$ Lu'luwatin R Aprilia*4 \\ Universitas Pendidikan Indonesia, Jl. Dr. Setiabudhi No 207 Bandung, 40154, Indonesia ${ }^{123}$ \\ Akademi Pariwisata NHI Bandung, Jl. Raya Lembang No. 112, 40391, Indonesia ${ }^{4}$
}

Email: nenirohaeni@upi.edu¹, yoyohjubaedah@upi.edu², nendenranirinekasari@upi.edu³, luluwatinrosdianaaprilia@gmail.com ${ }^{4}$

\begin{abstract}
An assessment standard in hospitality accommodation SMK used during lab practice indispensable. However, an assessment was used recently is not reference to current hotel SOP and the needs of each competency. This study is developing an assessment shaped e-rubric required by teachers in hospitality accommodation SMK. The purpose of this research is producing: 1) the manufacture and use of e-rubric assessment for hospitality accommodation competency guidelines, 2) the e-rubric and competency-based assessment approach on the skill in hospitality accommodation SMK. This research uses descriptive methods with research and development approach. The research includes preliminary study, the step of development, and experiment validation phase. A subject of study consisting of students and teachers' productive fields of hotel accommodation expertise. Data collection is done through interviews, observation, and competency test. Data analysis of this study was conducted in accordance with the procedures and characteristic of the lab data; both data analyzed quantitatively and qualitatively. A manually performance assessment that commonly used can be developed become e-rubric assessment by teachers in their schools and when students are doing practice field work in hotels. The result show that validation of the manufacture and use of competency assessment e-rubric guidelines with an approach based on the hotel industry in vocational skills accommodation expressed very reasonable to implement.
\end{abstract}

Keywords: Competency-based assessment; e-rubric; hospitality accommodation; Vocational High School

\begin{abstract}
Abstrak
Alat penilaian yang standar di SMK Akomodasi Perhotelan yang digunakan saat praktikum sangat diperlukan. Alat penilaian yang ada saat ini belum mengacu pada SOP Hotel dan kebutuhan dari masingmasing kompetensi keahlian. Urgensi penelitian ini mengembangkan alat penilaian yang berbentuk erubric yang dibutuhkan guru SMK Akomodasi Perhotelan. Tujuan dari penelitian ini adalah menghasilkan: 1) Panduan Pembuatan dan Penggunaan E-rubric Assessment Bidang Akomodasi Perhotelan, 2) E-rubric dengan Pendekatan Competency Based Assessment Pada Bidang Keahlian Akomodasi Perhotelan di SMK. Penelitian ini mengunakan metode deskriptif dengan pendekatan Research and Development. Penelitian mencakup studi pendahuluan, tahap pengembangan dan tahap uji validasi. Subjek penelitian terdiri dari peserta didik dan guru produktif bidang keahlian akomodasi perhotelan. Teknik pengumpulan data dilakukan melalui wawancara, observasi, dan uji kompetensi. Analisis data penelitian dilakukan sesuai dengan prosedur dan karakteristik dari temuan data penelitian; untuk data kuantitatif dianalisis secara kuantitatif dan untuk data kualitatif dianalisis secara kualitatif. Alat penilaian kinerja yang biasa digunakan secara manual dapat dikembangkan menjadi e-rubric assessment oleh guru di sekolah maupun pada saat peserta didik sedang melakukan Praktek Kerja Lapangan di hotel. Hasil validasi terhadap panduan pembuatan dan penggunaan E-Rubric dengan Pendekatan Competency Based Assessment pada bidang keahlian akomodasi perhotelan di SMK dinyatakan sangat layak untuk diimplementasikan.
\end{abstract}

Kata Kunci: Akomodasi perhotelan; Competency-based assessment; e-rubric; Sekolah Menengah Kejuruan

* Corresponding author

Received: March 05, 2021; Revised: May 19,2021; Accepted: May 20, 2021 


\section{A. PENDAHULUAN}

Pendidikan memiliki peranan penting di dalam meningkatkan sumber daya manusia termasuk Sekolah Menengah Kejuruan (SMK). Target SMK dengan adanya perubahan kurikulum 2013 diharapkan mampu menciptakan strategi pengelolaan pendidikan yang lebih berkualitas, sehingga mampu menghasilkan lulusan yang berkualitas baik dilihat dari kualitas akademik mapupun non akademik serta mampu bersaing secara kompetitif di dunia kerja. SMK memiliki karakterisrik proses dan hasil pembelajaran lebih cenderung dalam bentuk kompetensi, karena lulusan SMK harus sesuai dengan tuntutan industri yang selalu berkembang. Tuntutan industri menginginkan dengan kompetensi teknis dengan sikap yang baik (Kustitik dan Hadi, 2016; Wibowo, 2016).

Akomodasi Perhotelan merupakan salah satu kompetensi keahlian yang dipersiapkan untuk memasuki dunia kerja yang profesional di bidang perhotelan. Tujuan kompetensi keahlian Akomodasi Perhotelan di SMK yaitu membekali peserta didik dengan pengetahuan, sikap, keterampilan agar kompeten di bidang perhotelan. Kurikulum SMK pada mata pelajaran terdiri dari mata perlajaran normatif, adaptif dan mata pelajaran produktif yang berkaitan dengan kompetensi Akomodasi Perhotelan. Mata pelajaran produktif berorientasi pada pembekalan keterampilan di bidang perhotelan sesuai tuntutan industri, sehingga pembelajarannya harus link and match dengan industri yang dapat mengacu pada Standar Kompetensi Kerja Nasional Indonesia (Jatmoko, 2013). Oleh karena itu, pembelajaran di SMK lebih difokuskan pada keterampilan (skill) bidang pekerjaan tertentu, misalnya di industri perhotelan yang berkaitan dengan psikomotor (Ixtianto dan Sutrisno, 2016).

Kompetensi Akomodasi Perhotelan merupakan bidang keahlian produktif yang didalamnya terdapat Mata Pelajaran Housekeeping yang salah satunya Praktik Manual Polishing. Pada kegiatan praktik ini menuntut kemampuan peserta didik pada aspek kinerja yang sudah dirumuskan dalam SOP Hotel. Standar Operasional Prosedur (SOP) merupakan suatu acuan untuk melaksanakan tugas pekerjaan sesuai dengan fungsi dan alat penilaian kinerja instansi dalam hal ini industri perhotelan sesuai prosedur kerja. SOP adalah dokumen tertulis tentang serangkaian instruksi kerja yang bertujuan agar pegawai menjaga konsistensi dan tingkat kinerja pegawai atau tim dalam organisasi unit kerja (Mandey, dkk., 2016).

Tujuan dari Mata Pelajaran Housekeeping adalah agar peserta didik menguasai di bidang keahlian Akomodasi Perhotelan untuk mempersiapkan peserta didik menjadi pekerja yang baik pada bidangnya. Mata Pelajaran Housekeeping memberikan bekal aspek kognitif, aspek psikomotor dan aspek afektif kepada peserta didik sesuai dengan kurikulum, sehingga peserta didik memiliki kompetensi sebagai room attendant. Room attendant adalah orang yang memegang peranan penting dalam mempersiapkan kamar yang bersih dan menyenangkan untuk ditempati oleh tamu (Lengkey, dkk., 2015). Room attendant harus mengerti dan memahami para tamu yang mempergunakan jasa pelayanan kamar karena memberikan kualitas pelayanan kepada tamu dengan menciptakan kesan yang baik kepada tamunya (Taviprawati, dkk, 2019).

Seorang room attendant harus memberikan pelayanan yang terbaik, karena dapat meningkatkan kualitas hotel itu sendiri. Melalui praktik Housekeeping peserta didik disiapkan untuk menjadi room attendant yang kompeten, dan guru pun dituntut untuk menilai hasil praktik peserta didik sesuai dengan Standar Operasional Prosedur (SOP) hotel. SOP adalah bagian dari peraturan tertulis yang membantu untuk mengontrol perilaku anggota organisasi. Standar Operasional Prosedur (SOP) mengatur cara pekerja untuk melakukan peran keorganisasiannya secara terus menerus dalam pelaksanaan tugas dan tanggung jawab organisasi (Rinekasari NR, Jubaedah Y, Sobariah SN; 2019).

Jubaedah (2009) dalam penelitiannya mengungkapkan bahwa instrumen penilaian untuk praktik menggunakan test tindakan berupa unjuk kerja meliputi tahapan persiapan, proses kerja dan hasil yang disesuaikan dengan Standar Kompetensi Nasional. Tujuan dari dibuatnya Standar Kompetensi Nasional sebagaimana diterapkan di Hotel adalah SOP, memberikan panduan atau pedoman kerja agar kegiatan dapat terkontrol, sehingga target yang ingin dicapai dapat terwujud secara maksimal.

Capaian kompetensi peserta didik perlu diukur melalui penilaian. Banyak ahli dalam penilaian pendidikan dan teori belajar telah sepakat bahwa penilaian merupakan bagian integral dari pengajaran, dan penilaian yang harus digunakan untuk mendukung pembelajaran peserta didik dalam proses belajar sehari-hari dalam pengajaran di kelas (Kustitik dan Hadi, 2016). Penilaian praktik akomodasi perhotelan 
perlu dinilai menggunakan alat penilaian yang disesuaikan dengan SOP hotel untuk mengetahui sejauh mana hasil praktik yang dicapai peserta didik.

Alat penilaian praktik harus sesuai dengan kompetensi dasar yang akan diukur dengan menyesuaikan indikator penilaian yang akan diuji. Selain itu, didasarkan pada peran penting penilaian dalam pembelajaran karena pelaksanaan penilaian dengan alat yang tepat dan baik dapat memberikan timbal balik yang sesuai bagi peserta didik. Instrumen penilaian harus memenuhi syarat dan mempresentasikan kompetensi yang akan dinilai serta memenuhi persyaratan teknis sesuai dengan bentuk instrumen yang digunakan (Jubaedah, 2009).

Salah satu alat evaluasi yang dapat digunakan dalam menilai kompetensi peserta didik pada bidang keahlian akomodasi perhotelan adalah rubrik. Rubrik merupakan panduan penilaian yang menggambarkan kriteria yang diinginkan guru dalam menilai atau memberi tingkatan dari hasil pekerjaan peserta didik. Rubrik harus memuat daftar karakteristik yang diinginkan yang perlu ditunjukkan dalam suatu pekerjaan peserta didik disertai dengan panduan untuk mengevaluasi masingmasing karakteristik tersebut (Setiawan, 2019). Rubrik adalah alat skoring untuk asesmen yang bersifat subjektif yang di dalamnya terdapat satu set kriteria dan standar yang berhubungan dengan tujuan pembelajaran yang akan diases ke peserta didik (Muktiarni, Ana, Yulia C, Jubaedah Y; 2029). Rubrik penilaian dapat diterapkan untuk mengukur kompetensi di SMK, seperti praktik Akomodasi Perhotelan yang sudah dibuat oleh guru dapat dikembangkan menjadi e-rubric penilaian dalam upaya lebih efektif dan efisien di dalam menilai praktik Akomodasi Perhotelan sesuai job performance yang ditunjukkan peserta didik.

Upaya untuk mendukung guru dalam mengembangkan e-rubric harus memiliki pengetahuan dan keterampilan yang berkaitan dengan teknologi dan perangkatnya berbasis digital, seperti web, aplikasi, software yang akan berkontribusi pada kemampuan mengembangkan produk yang memiliki nilai inovasi teknologi. Salah satu aplikasi yang dapat digunakan dalam mengembangkan penilaian berbasis digital adalah e-rubric. E-rubric merupakan alat penilaian yang dapat dikembangkan dengan cara membuat aplikasi yang disesuaikan dengan karakteristik kompetensi yang harus dinilai atau dengan cara memanfaatkan web secara online seperti smart rubric yang bisa diakses dan disesuaikan dengan kebutuhan tuntutan kriteria kinerja dari masing-masing mata pelajaran (Jubaedah Y, Yulia C, Muktiarni, Maosul A; 2020).

Penggunaan e-rubric dalam proses penilaian dapat menyimpan data lebih rapi, mengelola data maupun informasi dapat dilakukan lebih cepat, tepat dan akurat dibandingkan dengan penialian yang dilakukan manual belum berkomputerisasi (Sugamayana, 2018). Untuk mencapai upaya tersebut, seyogianya pihak sekolah memberikan fasilitas yang mendukung baik dalam bentuk peralatan komputer dan internet yang mudah diakses maupun pengetahuan bagi guru produktif melalui pelatihan penggunaan program aplikasi berbasis digital. Penggunaan e-rubric sebagai pedoman penilaian menjamin keakuratan instrument yang menggambarkan kriteria keberhasilan berdasarkan hasil yang diharapkan dan struktur tugas yang logis dan sistematis (Brookhart, 2013).

Sesuai dengan uraian latar belakang masalah, penelitian ini bertujuan untuk menghasilkan ERubric dengan pendekatan Competency-Based Assessment pada bidang Akomodasi Perhotelan di SMK. E-Rubric yang dihasilkan untuk diimplementasikan pada pelaksanaan uji kompetensi di SMK pada keahlian housekeeping department.

E-Rubric dapat dikembangkan dengan cara memanfaatkan aplikasi SmartRubric yang sudah tersedia atau dengan membuat Web aplikasi rubrik yang mengakomodasi karakteristik kompetensi kerja sebagai room attendant di Housekeeping Department. Aspek yang dinilai pada performance assessment mencakup tahap persiapan, proses dan hasil pada kompetensi sesuai dengan materi uji. (Jubaedah $Y$, Rohaeni N, Rinekasari N. R, 2019), (Rohaeni N, Jubaedah Y, Rahmah A.A, 2019), (Jubaedah Y, Rohaeni N, Rinekasari N.R, Rohmah, I., 2018).

\section{B. METODE PENELITIAN}

Dalam penelitian ini menggunakan pendekatan Research and Development (R\&D) untuk menjawab masalah penelitian yang telah dirumuskan. Langkah penelitian Research and Development 
dalam penelitian ini meliputi tiga tahap, yaitu : (1) Studi Pendahuluan, (2) Pengembangan Model dan (3) Uji Validasi Model.

Partisipan dalam penelitian ini terdiri dari: Guru SMK Bidang Keahlian Akomodasi Perhotelan (SMK Negeri Kota Bandung), Praktisi Industri Perhotelan Bidang Housekeeping Department (Hemangini Hotel Kota Bandung) dan Dosen Universitas Pendidikan Indonesia sebagai akademisi di bidang Perhotelan.

Teknik pengumpulan data pada studi pendahuluan menggunakan wawancara, observasi, dan studi dokumentasi. Wawancara dilakukan kepada guru SMK Bidang Keahlian Akomodasi Perhotelan untuk memperoleh data tentang analisis kebutuhan dalam pengembangan e-rubric untuk uji kompetensi di SMK. Observasi dilakukan pada kegiatan penilaian praktik kompetensi housekeeping department. Dokumentasi dilakukan terhadap alat penilaian yang sudah ada dan biasa digunakan pada kompetensi housekeeping department di SMK Akomodasi Perhotelan.

Teknik pengumpulan data pada tahap pengembangan, dilakukan ujicoba E-rubric yang dihasilkan melalui melalui ujicoba terbatas di SMK Negeri 9 Kota Bandung pada praktik kompetensi Manual Polishing meliputi tahap persiapan, proses dan hasil praktik. Teknik pengumpulan data pada tahap uji model dilakukan uji validasi melalui expert judgement E-Rubric asesmen untuk menguji kelayakan dari E-Rubric tersebut melalui validasi ahli.

Analisis data dilakukan sesuai dengan karakteristik data penelitian; untuk data kualitatif dianalisis dengan cara dideskripsikan secara naratif dan untuk data kuantitatif dianalisis melalui perhitungan persentase.

\section{HASIL DAN ANALISIS}

Hasil studi pendahuluan menunjukkan bahwa, alat penilaian yang sudah ada dan sudah dipergunakan secara manual, dapat dikembangkan menjadi e-rubric untuk memudahkan dalam melakukan assessment oleh guru, baik pada saat uji kompetensi di sekolah maupun ketika peserta didik sedang melakukan praktik kerja lapangan di hotel. E-rubric merupakan alat penilaian yang dapat dikembangkan oleh guru sesuai tahapan kerja pada aplikasi digital yang terdapat pada smartphone ataupun laptop. Guru dapat memanfaatkan teknologi digital pada penilaian kinerja di pendidikan kejuruan, seperti pelaksanaan uji kompetensi di SMK Akomodasi Perhotelan.

Alat penilaian kinerja yang dipersiapkan untuk membantu dalam pembuatan E-Rubric dengan pendekatan Competency-based Assessment pada bidang keahlian Akomodasi Perhotelan di SMK mengadopsi dari luaran penelitian dalam bentuk Hak Cipta (Rohaeni N, Jubaedah Y, Fithriturrohmi Fithriturrohmi SY; 2019). Alat tersebut merupakan alat penilaian kinerja pada praktik manual polishing yang sudah dipergunakan secara manual oleh Guru Mata Pelajaran Housekeeping. Praktik manual polishing merupakan praktik pembersihan area umum secara manual yang mencakup praktik wood polishing, metal polishing dan leather polishing. Pelaksanaan praktik manual polishing dimulai dari tahap persiapan, proses pelaksanaan dan hasil praktik.

Untuk memperoleh alat penilaian kinerja praktik manual polishing yang standar, maka dilakukan kembali expert jugment sesuai dengan aspek kelengkapan persyaratan alat penilaian kinerja, aspek kesesuaian pelaksanaan praktik manual polishing dan aspek pengolahan nilai hasil praktik manual polishing.

Hasil validasi kelengkapan persyaratan alat penilaian kinerja manual polishing terdiri dari 3 syarat instrumen penilaian yaitu substansi, konstruksi dan bahasa. Hasil validasi pada aspek kelayakan alat penilaian kinerja praktik manual polishing memperoleh nilai sebesar $100 \%$ dan termasuk pada kategori sangat layak. Hasil validasi aspek penilaian pada pelaksanaan praktik manual polishing mencakup tahap persiapan praktik, tahap pelaksanaan praktik, dan hasil praktik manual polishing. Tahap persiapan praktik manual polishing memperoleh nilai sebesar $100 \%$ dan dapat dikategorikan sangat layak. Hasil validasi penilaian tahap pelaksanaan praktik manual polishing ini memperoleh nilai sebesar $100 \%$ dan termasuk pada kategori sangat layak. Hasil validasi pada penilaian hasil praktik manual polishing memperoleh nilai sebesar $100 \%$ yang berarti rancangan alat penilaian kinerja pada penilaian hasil praktik manual polishing dinyatakan sangat layak. 
Tabel 1. Alat Penilaian Kinerja pada Praktik Manual Polishing

\begin{tabular}{|c|c|c|c|}
\hline \multirow[t]{2}{*}{ No } & \multirow{2}{*}{ INDIKATOR KEBERHASILAN } & \multicolumn{2}{|c|}{ KRITERIA KEBERHASILAN } \\
\hline & & $\mathbf{K}$ & BK \\
\hline \multirow[t]{13}{*}{ A } & \multicolumn{3}{|l|}{ Persiapan Praktik Manual Polishing } \\
\hline & \multicolumn{3}{|l|}{ Kelengkapan Uniform } \\
\hline & a. Rambut laki-laki tidak melebihi kerah uniform dan daun telinga & & \\
\hline & b. Perempuan menggunakan hair net & & \\
\hline & $\begin{array}{l}\text { c. Perempuan yang berkerudung, menggunakan kerundung berwarna } \\
\text { hitam }\end{array}$ & & \\
\hline & d. Menggunakan name tag & & \\
\hline & e. Menggunakan ikat pinggang & & \\
\hline & f. Tidak menggunakan perhiasan & & \\
\hline & g. Menggunakan sepatu dan kaus kaki berwarna hitam & & \\
\hline & Kebersihan dan Kerapihan Penampilan Diri & & \\
\hline & a. Rambut disisir rapi & & \\
\hline & b. Kuku dipotong pendek dan bersih & & \\
\hline & c. Tidak memakai make up yang berlebihan & & \\
\hline \multirow[t]{12}{*}{ B } & \multicolumn{3}{|l|}{ Proses Praktik Wood Polishing } \\
\hline & \multicolumn{3}{|l|}{ Sistematika Kerja } \\
\hline & a. Menyiapkan dust cloth dan bottle spayer & & \\
\hline & b. Menyiapkan furniture polish & & \\
\hline & c. Membersihkan permukaan furniture dari debu & & \\
\hline & d. Menyemprotkan wood polisher pada dust cloth terlebih dahulu & & \\
\hline & $\begin{array}{l}\text { e. Melakukan pemolesan pada furniture dengan mengikuti alur atau urat } \\
\text { kayu secara merata }\end{array}$ & & \\
\hline & f. Melakukan pemeriksaan terhadap furniture yang sudah dibersihkan & & \\
\hline & \multicolumn{3}{|l|}{ Aspek Hygiene dan Keselamatan Kerja } \\
\hline & a. Menggunakan masker & & \\
\hline & b. Membersihkan kembali dust cloth yang sudah digunakan & & \\
\hline & c. Menyimpan kembali peralatan dan bahan pembersih ke storage & & \\
\hline \multirow[t]{14}{*}{$\mathbf{C}$} & \multicolumn{3}{|l|}{ Proses Praktik Metal Polishing } \\
\hline & \multicolumn{3}{|l|}{ Sistematika Kerja } \\
\hline & a. Menyiapkan soft cloth & & \\
\hline & b. Menyiapkan metal polish & & \\
\hline & c. Membersihkan permukaan objek dari debu & & \\
\hline & d. Menutup permukaan lain agar tidak terkena metal polisher & & \\
\hline & e. Melakukan pemolesan secara merata dengan cara memutar & & \\
\hline & f. Membersihkan bekas cairan metal polisher dengan soft cloth & & \\
\hline & $\begin{array}{l}\text { g. Melakukan pemeriksaan terhadap permukaan metal yang sudah } \\
\text { dibersihkan }\end{array}$ & & \\
\hline & \multicolumn{3}{|l|}{ Aspek Hygiene dan Keselamatan Kerja } \\
\hline & a. Menggunakan masker & & \\
\hline & b. Menggunakan hand glove & & \\
\hline & c. Membersihkan kembali soft cloth yang sudah digunakan & & \\
\hline & d. Menyimpan kembali peralatan dan bahan pembersih ke storage & & \\
\hline \multirow[t]{9}{*}{ D } & \multicolumn{3}{|l|}{ Proses Praktik Leather Polishing } \\
\hline & Sistematika Kerja & & \\
\hline & a. Menyiapkan shoe brush dan soft cloth & & \\
\hline & b. Menyiapkan shoe polish, alkohol dan kapas & & \\
\hline & $\begin{array}{l}\text { c. Membersihkan sepatu dari debu dan kotoran pada bagian dalam dan } \\
\text { alas sepatu }\end{array}$ & & \\
\hline & d. Mengambil shoe polish dengan cara memutar (tidak dicolek) & & \\
\hline & e. Melakukan pemolesan dengan gerakan melingkar dengan shoe brush & & \\
\hline & f. Menggosok sepatu menggunakan soft cloth & & \\
\hline & $\begin{array}{l}\text { g. Melakukan pemeriksaan terhadap permukaan sepatu yang sudah } \\
\text { dibersihkan }\end{array}$ & & \\
\hline
\end{tabular}




\begin{tabular}{|c|c|c|c|}
\hline \multirow{2}{*}{ NO } & \multirow{2}{*}{ INDIKATOR KEBERHASILAN } & \multicolumn{2}{|c|}{ KRITERIA KEBERHASILAN } \\
\hline & & $\mathbf{K}$ & BK \\
\hline & Aspek Hygiene dan Keselamatan Kerja & & \\
\hline & a. Menggunakan hand glove & & \\
\hline & b. Membersihkan kembali shoe brush dan soft cloth yang sudah digunakan & & \\
\hline & c. Menyimpan kembali peralatan dan bahan pembersih ke storage & & \\
\hline \multirow[t]{10}{*}{$\mathbf{E}$} & \multicolumn{3}{|l|}{ Hasil Praktik Manual Polishing } \\
\hline & \multicolumn{3}{|l|}{ Hasil Praktik Wood Polishing } \\
\hline & a. Kondisi furnitur terlihat mengkilap, bersih, rapi dan wangi & & \\
\hline & b. Ketepatan waktu praktik selama 20 menit & & \\
\hline & \multicolumn{3}{|l|}{ Hasil Praktik Metal Polishing } \\
\hline & a. Kondisi metal terlihat mengkilap, bersih dari debu dan bekas sidik jari & & \\
\hline & b. Ketepatan waktu praktik selama 20 menit & & \\
\hline & \multicolumn{3}{|l|}{ Hasil Praktik Leather Polishing } \\
\hline & $\begin{array}{l}\text { a. Kondisi permukaan sepatu yang sudah dibersihkan terlihat mengkilap } \\
\text { dan bersih dari debu dan kotoran }\end{array}$ & & \\
\hline & b. Ketepatan waktu praktik selama 20 menit & & \\
\hline
\end{tabular}

\section{Penggunaan E-Rubric Assessment untuk bidang Akomodasi Perhotelan}

Pengembangan E-Rubric dengan Pendekatan Competency-Based Assessment pada Bidang Keahlian Akomodasi Perhotelan di SMK dimulai dengan pemahaman terhadap sistem operasi laptop, browsing internet, pemahaman dalam mengakses aplikasi web smartrubric, kemudahan penggunaan erubrik, Sistem operasi smartphone, Proses sign in/sign up, Privasi data dan kepemilikan sampai Pengarsipan, penyimpanan, dan ekspor data.

Alat penilaian yang sudah ada dan sudah dipergunakan secara manual, dapat dikembangkan dengan e-rubrik untuk memudahkan dalam melakukan assessment oleh guru, baik di sekolah maupun ketika peserta didik sedang melakukan praktek kerja lapangan di hotel.

Pembuatan E-Rubric dengan pendekatan Competency-based Assessment pada bidang keahlian Akomodasi Perhotelan di SMK dimulai dengan pembuatan akun smartrubric terlebih dahulu. Tata cara membuat akun sebagai langkah awal untuk membuat alat penilaian digital dengan menggunakan aplikasi smartrubric (Pinemarten Education Ltd. (2015). https://www.smartrubric.com/), yaitu sebagai berikut:

1. Sebelum membuat alat penilaian, hal yang pertama harus dilakukan adalah menyusun deskripsi alat penilaian sesuai dengan identitas mata pelajaran yang dibuat. Berikut keterangan kolom deskripsi yang harus diisi:

- Name : Masukan nama alat penilaian praktik.

- Subject : Kelompok mata pelajaran.

- Select course : Nama mata pelajaran.

- Notes : Keterangan alat penilaian (optional)

Berikut contoh pengisian deskripsi alat penilaian:

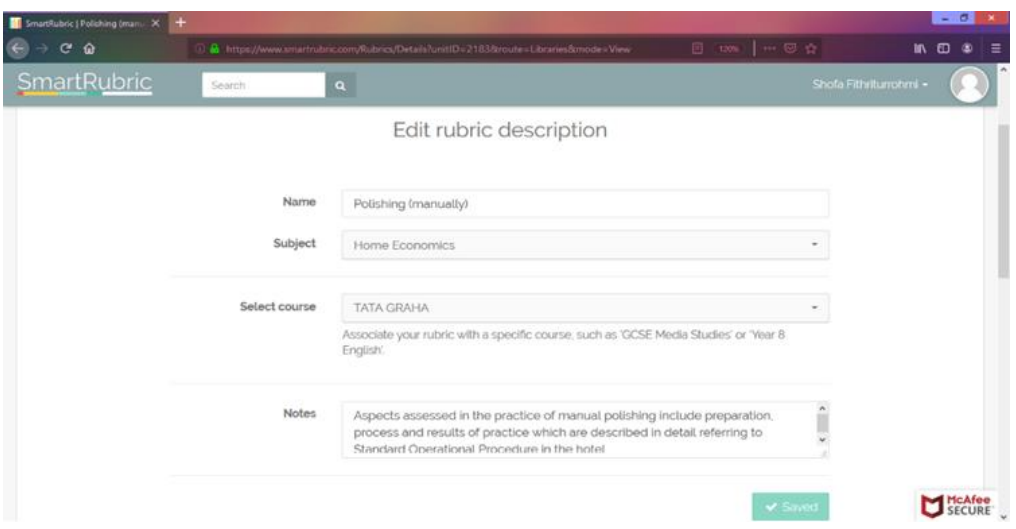

Gambar 1. Penyusunan Deskripsi Alat Penilaian 
2. Untuk mengubah isi alat penilaian klik menu "matrix" lalu klik "edit".

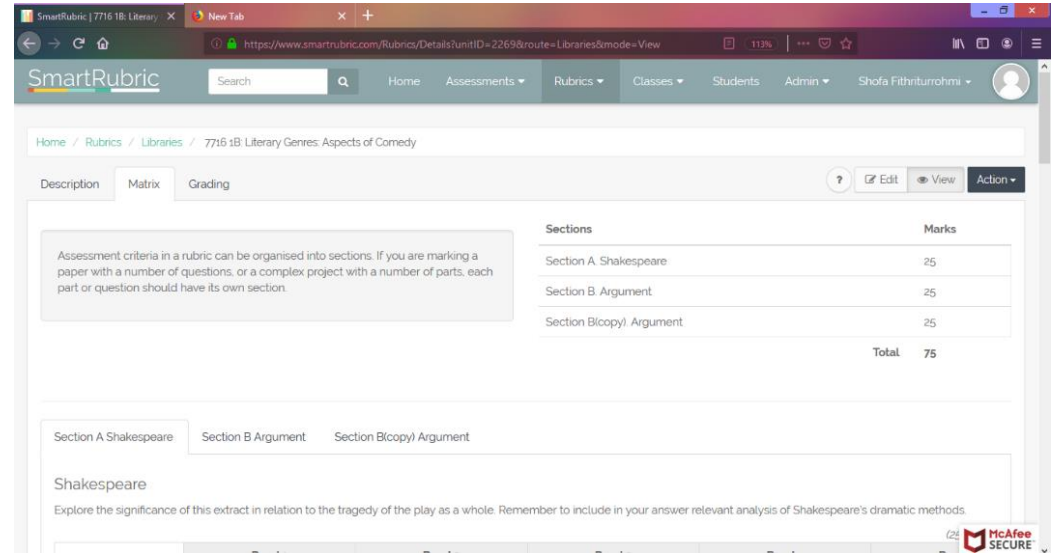

Gambar 2. Perubahan Isi Alat Penilaian

3. Pada tahap ini, mengisi kolom yang tersedia sesuai dengan alat penilaian yang dibuat

- Section Number : nomor bagian soal

- Section Title

- Weight

- Marks

- Full text : Judul bagian soal : bobot pertanyaan : total nilai yang dicapai : keterangan aspek aspek yang akan dinilai

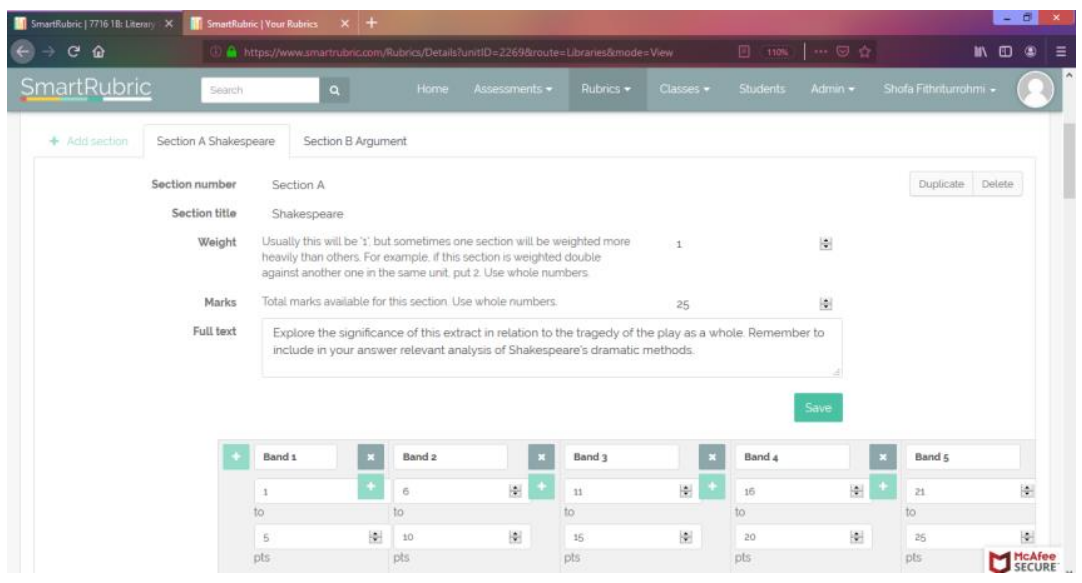

Gambar 3. Pengisian Alat Penilaian Sesuai Kolom Yang Disediakan 
4. Struktur menu untuk alat penilaian

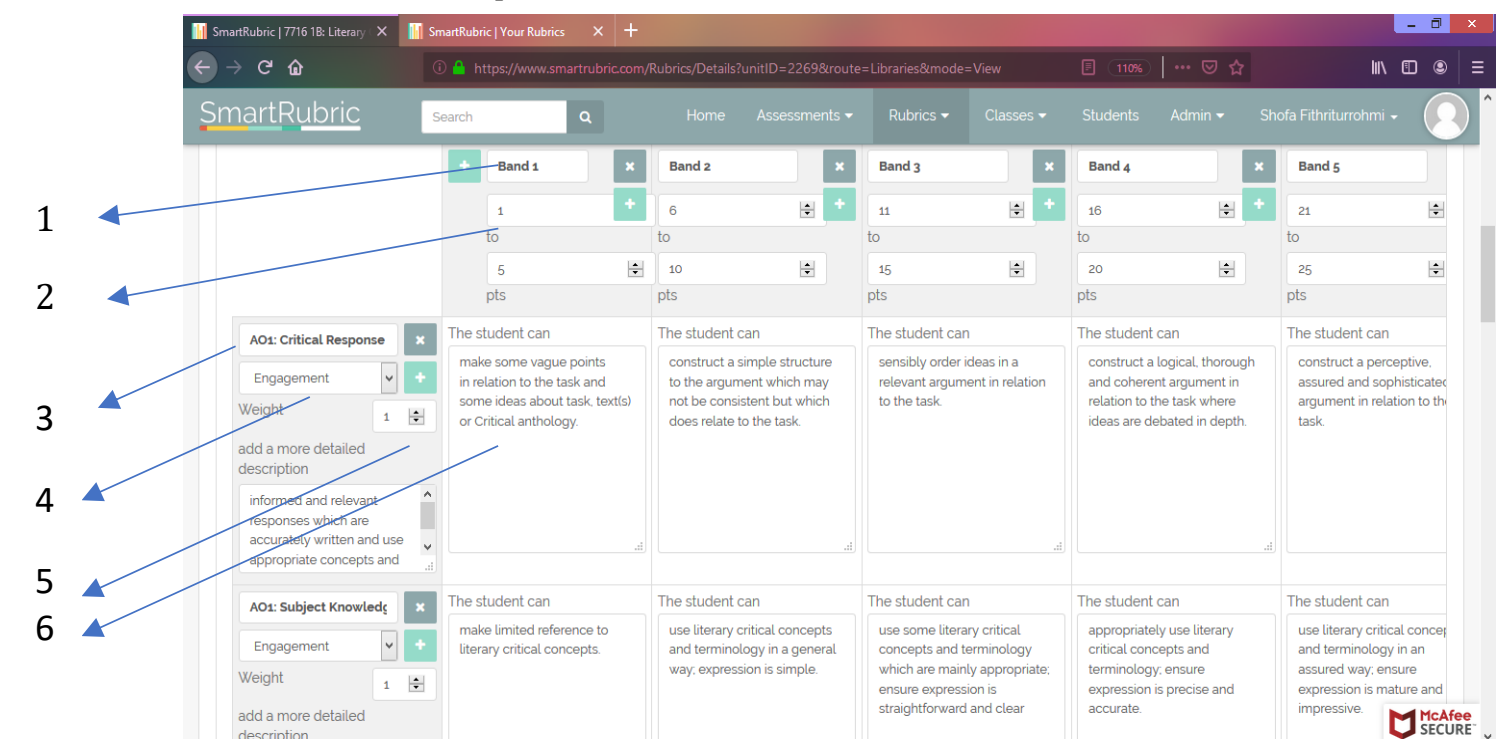

Gambar 4. Struktur menu untuk alat penilaian

Keterangan :

Nomor 1 Kriteria keberhasilan

Salah satu contoh kriteria keberhasilan yang dapat digunakan yaitu "competent" dan "not competent"

Kriteria keberhasilan dapat disesuaikan dengan kebutuhan aspek yang dinilai

Nomor 2 Bobot yang dicapai

Contoh : skor untuk "competent" = 10 dan skor untuk "not competent" = 0

Nomor 3

Indikator keberhasilan

Acuan penilaian untuk menentukan peserta didik telah berhasil menguasai kompetensi

Nomor 4 Ranah indikator keberhasilan

ranah indikator keberhasilan disesuaikan dengan kompetensi pada alat penilaian seperti, skill, Bahasa, analisis dan sebagainya

Nomor 5 Skor soal

Contoh:

skor soal untuk indikator keberhasilan "Rambut laki-laki tidak melebihi kerah uniform dan daun telinga" adalah 1

Nomor 6 Keterangan Indikator keberhasilan yang harus dicapai

Contoh :

Rambut peserta didik laki-laki harus disisir dengan rapi tidak melebihi kerah uniform dan daun telinga

Untuk lebih jelasnya, contoh alat penilaian yang sudah diisi dapat dilihat pada Gambar 5. 


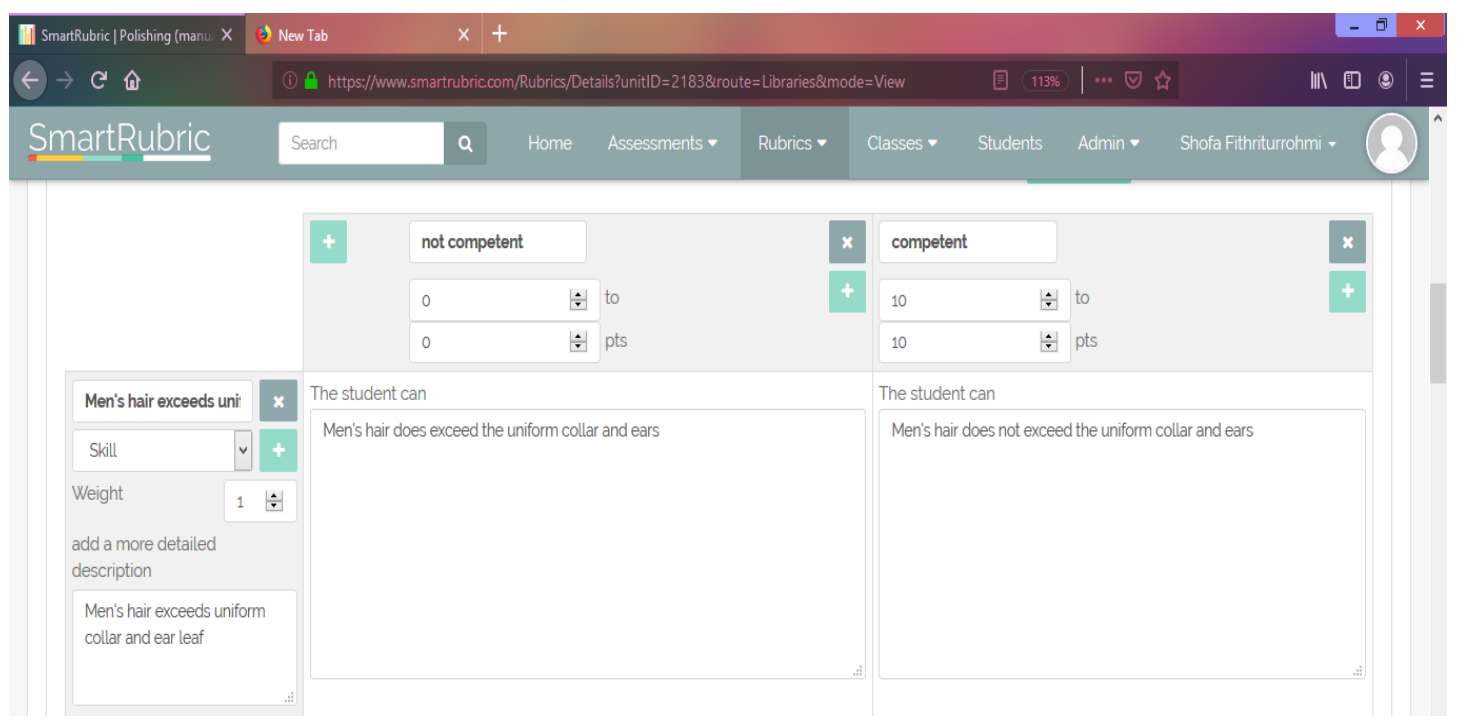

Gambar 5. Contoh Alat Penilaian dalam E-rubric

Penskoran kriteria keberhasilan dinyatakan dengan "Kompeten (K)" mendapatkan skor 1 dan "Belum Kompeten (BK)" mendapatkan skor 0. Peserta didik dinyatakan "Kompeten", apabila seluruh aspek kompetensi pada indikator yang harus dikuasi sudah dinyatakan "Kompeten" seluruhnya.

Pembuatan E-Rubric dengan pendekatan Competency-based Assessment pada bidang keahlian Akomodasi Perhotelan di SMK dimulai dengan pembuatan akun smartrubric terlebih dahulu. Tata cara membuat akun sebagai langkah awal untuk membuat alat penilaian digital dengan menggunakan aplikasi smartrubric (Pinemarten Education Ltd., 2015). Aplikasi ini setelah diadaptasi pada pengembangan rubrik penilaian pada pelaksanaan uji kompetensi, diperoleh temuan bahwa aspek-aspek yang harus diisi prosedurnya terlalu kompleks (kurang praktis), sehingga guru harus banyak melakukan penyesuaian pada proses pengisiannya. Dari temuan ini perlu direkomendasikan untuk dilakukan penelitian lanjutan pada pengembangan aplikasi rubrik penilaian berabsis Web yang lebih praktis dan sistematis sesuai karakteriktik kinerja pada kompetensi housekeeping department dan kebutuhan guru DI SMK Akomodasi Perhotelan. Alat penilaian yang dikembangkan berbasis digital atau e-rubric ini untuk memberikan kenyamanan kepada guru pada saat melaksanakan penilaian dengan memanfaatkan aplikasi pada website.

\section{SIMPULAN}

1. E-rubric dengan Pendekatan Competency-Based Assessment pada Bidang Keahlian Akomodasi Perhotelan di SMK yang telah dikembangkan; diperoleh temuan sangat layak berdasarkan hasil expert judgement yang dianalisis dari subsatansi, konstruksi dan bahasa.

2. Pengguanaan aplikasi SmartRubric dalam pengembangan e-rubric dengan Pendekatan CompetencyBased Assessment pada Bidang Keahlian Akomodasi Perhotelan di SMK diperoleh temuan kurang praktis, sehingga perlu dilakukan penelitian lanjutan pada pengembangan aplikasi berbasis Web yang lebih praktis dan sesuai dengan karakteristik kompetensi housekeeping department di SMK.

\section{DAFTAR REFERENSI}

Atmaja, B. S. D. (2018). TA: Rancang Bangun Aplikasi Penilaian Hasil Pembelajaran Siswa dengan Kurikulum 2013 Berbasis Web (Doctoral dissertation, Institut Bisnis dan Informatika Stikom Surabaya). 
Brookhart, S. M. (2013). How to Create and Use Rubrics for Formative Assesment and Grading. Journal of Experimental Psychology: General (Vol. 136). USA: ASCD. 4. Eyal, L. (2012). Digital Assessment Literacy - the Core Role of the Teacher in a Digital

Ixtiarto, B. \& Sutrisno, B. (2016). Kemitraan Sekolah Menengah Kejuruan Dengan Dunia Usaha dan Dunia Induatri (Kajian Aspek Pengelolaan Pada SMK Muhammadiyah 2 Wuryantoro Kabupaten Wonogiri), Jurnal Pendidikan Ilmu Sosial, Vol. 26, No. 1, 57-69.

Jatmoko, D. (2013). Relevansi Kurikulum SMK Kompetensi Keahlian Teknik Kendaraan Ringan Terhadap Kebutuhan Dunia Industri Di Kabupaten Sleman. Jurnal Pendidikan Vokasi, Vol. 3, Nomor 1, 1-13.

Jubaedah, Y., Yulia, C., Muktiarni, M., \& Maosul, A. (2020, January). Usability testing electronic rubric of performance assessment. In Journal of Physics: Conference Series (Vol. 1456, No. 1, p. 012016). IOP Publishing.

Jubaedah Y, Rohaeni N, Rinekasari N.R. (2019). Competency-based Assessment Model on Job Performance in Housekeeping Department Aprrenticeship. Bandung : Proceedings of the 5th UPI International Conference on Technical and Vocational Education and Traiining (ICTVET 2018).

Jubaedah Y, Rohaeni N, Rinekasari N.R, Rohmah I. (2018). Model Competency Based Assessment Pada Pengembangan Job Performance Public Area di Housekeeping Department. Jakarta : Jurnal Kesejahteraan Keluarga dan Pendidikan Vol. 5 No. 2. Oktober 2018.

Jubaedah, Y., (2009). Model Penilaian Keahlian Tata Busana Berbasis Standar Kompetensi Nasional di Sekolah Menengah Kejuruan. Bandung: Sekolah Pascasarjana Universitas Pendidikan Indonesia.

Kustitik, K., \& Hadi, S. (2016). Pengembangan perangkat penilaian autentik mata pelajaran prakarya dan kewirausahaan di SMK. Jurnal Pendidikan Vokasi, 6(2), 184-197.

Lengkey, J., Towoliu, B.I., \& Djamali, R., (2015). Pengaruh Kualitas Pelayanan Room Attendant Terhadap Kepuasan Tamu Hotel. Jurnal Hospitaliti dan Pariwisata, Volume 2, Nomor 1, 25-40.

Mandey, A., Towoliu, R.D., \& Andih, D.C., (2016). Analisis Penerapan Standar Operasional Prosedur Room Section Pada Hotel Berbintang. Jurnal Hospitaliti dan Pariwisata, Volume 3, Nomor 1, 91-104.

Muktiarni, M., Ana, A., Yulia, C., \& Jubaedah, Y. (2019, December). Electronic Rubrics Design to Assess Student Competence in Vocational Education. In 1st Vocational Education International Conference (VEIC 2019) (pp. 257-261). Atlantis Press.

Pinemarten Education Ltd. (2015). https://www.smartrubric.com/

Rinekasari, N. R., Jubaedah, Y., \& Sobariah, S. N. (2019). Standard Operating Procedure of Housekeeping Adaptation: The Development of Assessment Tools in Cleaning Bathroom Practices at Vocational High School. KnE Social Sciences, 150-161.

Rohaeni N, Jubaedah Y, Fithriturrohmi. (2019). Alat Penilaian Kinerja Pada Praktik Manual Polishing Dengan Pendekatan Competency Based Assessment. Surat Pencatatan Ciptaan: 0001728877.

Rohaeni N, Jubaedah Y, Rahmah A.A. (2019). Competency Based Assessment Pada Perancangan Alat penilaian Kinerja Praktik Making Bed Di Housekeeping Department. Jakarta : Jurnal Kesejahteraan Keluarga dan Pendidikan Vol 6 No. 01. April 2019.1

Setiawan, S. (2019). Pengertian Rubrik, Tujuan, Jenis, Isi, Macam, Contoh, Para Ahli. Terdapat di [On line] https://www.gurupendidikan.co.id. (18 Agustus 2019).

Taviprawati, E., Sembiring, V.A., \& Tarigan, E., (2019). Analisis Kualitas Pelayanan Room Attendant Terhadap Kepuasan Pelanggan Di Hotel Inter-Continental Jakarta MID Plaza. Jurnal Ilmiah Pariwisata, Volume 24, No. 1, 1-11.

Wibowo, N. (2016). Upaya Memperkecil Kesenjangan Kompetensi Lulusan Sekolah Menengah Kejuruan Dengan Tuntutan Dunia Industri. Jurnal Pendidikan Teknologi dan Kejuruan, Vol. 23, No. 1, 45-50. 